\section{Compression materials in chronic edema}

\section{Franz Schingale \\ Medical Director, Lympho-Opt Clinic, Pommelsbrunn, Germany}

\section{Introduction}

Edema is an excess of interstitial fluid and is an important sign of ill health in clinical medicine. The developing of edema finds its reason in the lymph system. But not all edema are lymphedema.

Edema develops when the microvascular (capillary and venules) filtration rate exceeds lymph drainage for a sufficient period, either because the filtration rate is high or because lymph flow is low or a combination of the two.

\section{The difference of lymphatic insufficiency}

\section{High volume insufficiency}

Depends on an overload of fluid like in inactivity edema, CVD stage 1 (C3, CEAPclassification), hypoproteinemia and premenstrual syndrome. There is an overload of water with normal function of the lymph vessels. We call it dynamic or high volume insufficiency, the transport capacity (TC) is normal and the lymphatic load (LL) is higher than the TC.

\section{Mechanical or low volume insuffi- ciency}

The lymph system is damaged and as result a lymphedema develops. Lymphedema means a primary or secondary damage of the lymph system, the TC is lower than normal, the LL is in normal range.

\section{Safety function insufficiency}

The TC is normal at the beginning but due to the growing of the LL the TC starts to go down, for example in acute inflammation, where the tissue hormones will enlarge the lymph vessels or in right heart insufficiency, where the lymph inflow to the right heart is blocked.

\section{Localisation}

Chronic edema can appear not only at the limbs but at the whole body such as face, thorax, abdomen and genitals and in all body cavities.

\section{Why compression?}

Reasons for compression are: ${ }^{1-3}$ i) reduction in capillary filtration rate (CFR); ii) shift of fluid into non-compressed parts of the body; iii) increase of lymphatic drainage (passive and active calf muscle contractions); iv) increased lymphatic contractions (vasomotion); v) reduction of dilatation and by that; vi) better valve function; vii) improvement of the venous pump in patients with veno-lymphatic dysfunction; viii) breakdown of fibrosclerotic tissue (increased mobilisation/transport of proteins?).

Compression produces a defined interface pressure to reduce the CFR and increase the venous and lymphatic drainage. To reduce the edema in lymphatic insufficiency No 2 and 3 it is the most important point to choose the right compression material. ${ }^{4-7}$ There are evidences, that inelastic material improves the function more than elastic..$^{8-15}$

\section{Different types of compression mate-} rials

\section{Bandages}

For edema reduction it is essential to use different types of compression material with high working pressure and low resting pressure, ${ }^{9}$ that means inelastic material, while elastic material is used in the phase of maintenance. Relevant to these pressure qualities are the number of bandage layers, the tension with which these layers are applied, and most importantly the type of bandage used. ${ }^{14}$

\section{Long stretched}

Those are elastic bandages, made out of cotton wool in mixture with polyamid and elastane in different combinations depending on the elasticity with high pressure in resting position, during muscle work the elasticity yields and reduces the working pressure

Advantage: the elastic material changes to the change of circumference. It is used in the case of poor edema without growing to keep the result.

Disadvantage: elastic material allows the edema to grow.

\section{Short stretched and ultra short strechted}

This kind of compression material out of cotton wool or viscose and polyamid produces high working and low resting pressure (Figure 1).

Advantage: due to high working pressure there is a good reduction of the edema

Disadvantage: fast edema reduction, bandage will slip very fast.
Correspondence: Franz Schingale, Medical Director, Lympho-Opt Clinic, Happurgertsr 15, 91224 Pommelsbrunn, Germany. E-mail: schingale@lympho-opt.de

Conference presentation: International Compression Club (ICC) Meeting, Rotterdam, 2018.

This work is licensed under a Creative Commons Attribution 4.0 License (by-nc 4.0).

CC Copyright F. Schingale, 2018

Licensee PAGEPress, Italy

Veins and Lymphatics 2018; 7:7981

doi:10.4081/vl.2018.7981

\section{Unna-Boot (Zinc pasted bandages)}

Stiff material out of cotton wool and polyamid, sometimes gauze, imprignated with zincoxid and calamine, sticks on the skin, does a very good reduction due to the stiffness, but will be loosen up after a few hours (Figure 2)..$^{5,16}$

Disadvantage: it cannot be used for a second time.

\section{Velcro devices}

Stiff material of a mixture from polyurethane, nylon and elasthane, good reduction of edema.

Advantage: very good reduction of edema, will slip as similar as short strechted bandages but can be readjusted by velcro closures. ${ }^{7,13}$ Some of them have an inbuilt pressure controlling system, so that the interface pressure can be controlled and be readjusted to the given pressure.

Disadvantage: it will slip during reduction. Advantage: can be readusted very fast by the patient himself.

\section{Material (different companies, different combinations of the fabrics)}

\section{Polyamide (PA, Nylon ${ }^{\circledR}$, Perlon $\left.{ }^{\circledR}\right)$}

Polyamide fiber fabrics are resistant to aging, insects and rot, mothproof and resistant to microorganisms.

\section{Elastane (EL, Lycra $\left.{ }^{\circledR}\right)$}

This material consists of $85 \%$ polyurethane (PU). The highly elastic fibers are resistant to almost all dilute acids and alkalis as well as oils and fats. They are resistant to aging, light and temperatures up to $150^{\circ} \mathrm{C}$.

\section{Cotton}

The cotton $(\mathrm{CW})$ is the seed hair of the 
annual, shrubby, usually 2-3 m high cotton plant of the family Malvaceae. Raw CW generally contains $83-85 \%$ pure cellulose $\mathrm{CW}$ is boil-proof and sterilizable; the static charge is low. The elasticity is about $40 \%$.

\section{Elastodiene (natural rubber)}

Raw material is the latex (natural latex) of the caoutchuk tree, which is obtained by cutting the bark. Elastodiene (ELA) is characterized by a particularly high elastic extensibility. It is, however, unstable against fats and many chemical substances. At high temperature (e.g., during sterilization) ELA is destroyed.

\section{Viscose (cotton, rayon)}

The cell wool, unlike native cotton, is a regenerated cellulose fiber, a chemical fiber. Viscose has a moisture content of 5 to $15 \%$ and is considered a substitute for cotton.

\section{Microfiber}

It is the general name for polyamide and polyester fibers with very low weight, i.e., $10,000-100,000 \mathrm{~m}$ of this fiber weigh $1 \mathrm{~g}$. They are thus much finer than natural fibers. Known materials are Tactel ${ }^{\circledR}$ and Trevira Finesse ${ }^{\circledR}$.

\section{Stockings}

\section{Round knitted}

Without seem, Circular knit is made by
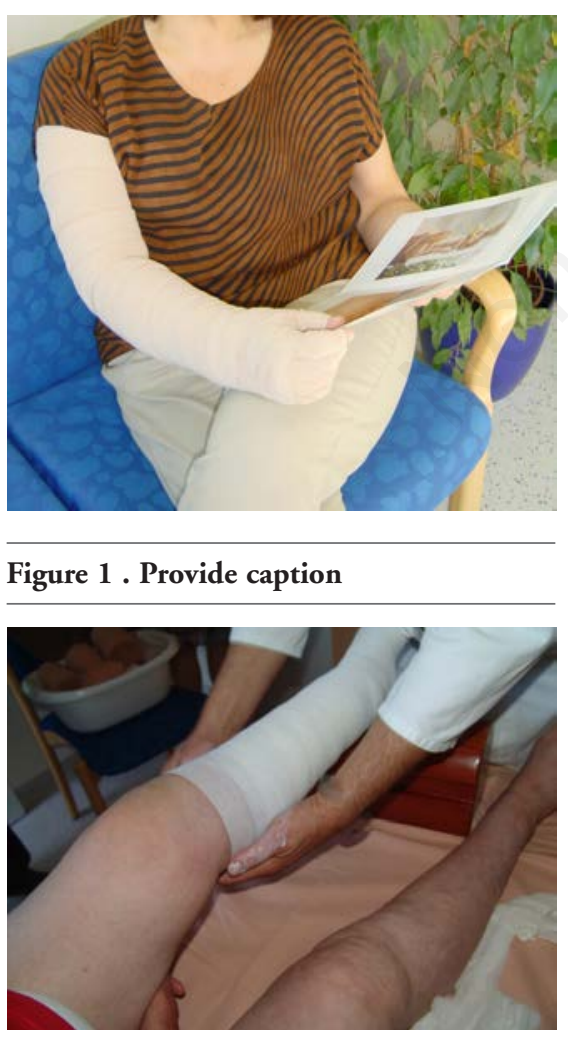

Figure 2 . Provide caption machines that knits the fabric in a continuous circle (tube); the weight is light. The fabric is thin, changes in the circumference are only possible by extending the fabric what means the bigger the circumference of an extremity the bigger the mesh width.

\section{Flatknitted}

Flat knit is made with a machine that knits the fabric in sheets (or flat) with seem. The changes in circumference of the limb has a fabric with more meshes, so there is a better compression.

\section{Conclusions}

In dynamic insufficiency the compression will reduce the CFR. In most cases we will use roundknitted compression stockings. In cases of generalised dynamic insufficiency the essentially treatment is to treat the cause such as hypoproteinaemia or hormonal reasons.

Mechanical insufficiency has to be treated in three phases(previous two phases): phase of reduction, phase of transition and phase of maintenance. For the different phases different compression material is recommended. . $^{10,11,17,18}$

Safety function insufficiency: First aim is to reduce the acting agents. Treatment of those diseases are similar to lymphedematreatment. Caution with compression in acute inflammation and right heart insufficiency.

\section{References}

1. Damstra RJ, Brouwer ER, Partsch H. Controlled, comparative study of relation between volume changes and interface pressure under short-stretch bandages in leg lymphedema patients. Dermatol Surg 2008;34:773-8; disc. 778-9.

2. Elwell R. An overview of the use of compression in lower-limb chronic oedema. Br J Community Nurs 2016; 21:36-40.

3. Hobday A. Use of compression therapy in patients with lymphoedema. Nurs Stand 2016;30:50-8.

4. Hopkins A. A community nursing guide: multilayer lymphoedema bandaging. Br J Community Nurs 2008; 13:S18, S20-4.

5. Kasseroller RG, Brenner E. A prospective randomised study of alginatedrenched low stretch bandages as an alternative to conventional lymphologic compression bandaging. Support Care
Cancer 2010;18:343-50.

6. King M, Deveaux A, White H, Rayson D. Compression garments versus compression bandaging in decongestive lymphatic therapy for breast cancerrelated lymphedema: a randomized controlled trial. Support Care Cancer 2012;20:1031-6.

7. Lamprou DA, Damstra RJ, Partsch H. Prospective, randomized, controlled trial comparing a new two-component compression system with inelastic multicomponent compression bandages in the treatment of leg lymphedema. ermatol Surg 2011;37:985-91.

8. Lulay GR. The chronicle lymphedema-an interdisciplinary challenge. MMW Fortschr Med 2014;156:44-5.

9. Partsch H, Damstra RJ, Mosti G. Dose finding for an optimal compression pressure to reduce chronic edema of the extremities. Int Angiol 2011;30:527-33.

10. Todd M. Compression hosiery choices for managing chronic oedema. $\mathrm{Br} \mathrm{J}$ Community Nurs 2015;20:318-20.

11. Ochalek K, Gradalski T, Szygula Z. Five-year assessment of maintenance combined physical therapy in postmastectomy lymphedema. Lymph Res Biol 2015;13:S54-8.

12. Partsch H. Indications for compression therapy in venous and lymphatic disease Consensus based on experimental data and scientific evidence under the auspices of the IUP. Int Angiol 2008; 27:S193.

13. Williams A. A review of the evidence for adjustable compression wrap devices. J Wound Care 2016;25:S242-7.

14. Flour M, Clark M, Partsch H, et al. Dogmas and controversies in compression therapy: Report of an International Compression Club (ICC) meeting, Brussels May 2011. Int Wound J 2012: $1-13$.

15. Mosti G. Stiffness of compression devices. Veins and Lymphatics 2013;2:e1-2.

16. Schingale F-J, Partsch H. Alginate hydrocolloid impregnated zinc paste bandages-an alternative in the management of lymphoedema? Veins and Lymphatics 2013;2:32-6.

17. Schingale F-J. Compliance improvement of compression therapy in patients with lymphedema. Veins and Lymphatics 2018;7:7635.

18. AWMF. German guidelines for phlebological compression bandages; 2010. Registrierungsnummer: 037-005, Entwicklungsstufe: S2. 